\section{Effects of instruction and interstimulus interval in human GSR conditioning*}

\author{
RICHARD P. SWENSON† and FRANCES A. HILL \\ University of Montana, Missoula, Mont. 59801
}

Facilitating and inhibiting sets were given to 72 human Ss in a classical galvanic skin response (GSR) conditioning situation employing a within-S design. Three groups of 24 Ss each were given 4 UCS adaptation trials followed by 10 acquisition and 16 extinction trials. Three different interstimulus intervals (ISI) were included as a between-S variable. Both acquisition and extinction data revealed that GSR magnitude on facilitatory trials was significantly larger than on inhibitory trials $(\mathrm{p}<.01)$. Results further indicated that differential responding in accord with instructional set was not dependent upon an extended CS-UCS interval.

The effect of Ss' sets and attitudes in the classical galvanic skin response (GSR) conditioning situation has been a frequent subject of investigation. Early research by Cook \& Harris (1937) and Mowrer (1938) demonstrated the importance of verbally induced set in affecting the outcome of GSR conditioning. Their research, as well as a large number of later studies, have supported the general conclusion that GSR magnitude can be reliably affected by sets and attitudes, induced either by instructions concerning the stimulus situation (e.g., Wickens, Allen, \& Hill, 1963) or by information concerning how to respond (e.g., Hill, 1967).

Consequently, it is now generally recognized that the different sets with which Ss are likely to enter the conditioning situation should be considered and controlled for. Only a few studies, however, have considered a need for investigating changes in Ss' sets and attitudes that may occur during the conditioning situation. In an experiment involving the perceptual disparity response, Grings \& Lockhart (1963) reported that some Ss tended to overrespond to changed stimulus conditions and to develop a persisting expectation of further change in conditions, often working in opposition to E's instructions. Also, Spence, Rutledge, \& Talbott (1963) discussed the importance of the effects the unexpected change in procedure from acquisition to extinction

*This paper is based on a thesis completed by the first author under the direction of the second author and submitted to the University of Montana in partial fulfillment of the requirements of the MA degree. Portions of this paper were reported at the meetings of the Rocky Mountain Psychological Association, Salt Lake City, Utah, 1970. The research was conducted while the first author was supported by a National Institute of Mental Health traineeship.

$\div$ Requests for reprints should be sent to Richard Swenson. Department of Psychology. University of Montana, Missoula, Mont. 59801. might have on $\mathrm{Ss}$ in classical eyelid conditioning. One aim of the present study was to investigate further the importance of within-session changes in Ss' sets and attitudes. For this purpose, a within-S design was employed. Response set was varied by instructing Ss either to try to facilitate or to inhibit their responses on different trials during the conditioning procedure, depending on the nature of a signal in the experimental room. Differential responding in accord with instructional set was predicted. An attempt was made to control for stimulus set by informing all $S s$ of the nature of the stimulus situation and of the changes in procedure (i.e., the switch from adaptation extinction) that would occur during the course of the experiment.

An additional objective was to investigate the relationship between interstimulus interval (ISI) and instructional set. It has previously been suggested (e.g., Hill, 1967) that mediational processes might be involved, and that a longer ISI might be more conducive to such processes. Accordingly, three ISIs $(500,2,000$, and $4,000 \mathrm{msec})$ were included as a between-S variable.

\section{SUBJECTS}

The Ss were 80 introductory psychology students who volunteered for this experiment with the knowledge that shock would be employed. The data of eight Ss were eliminated due to procedural errors, excessive base-level skin resistances, or equipment malfunction. Of the remaining 72 Ss used in the experiment, 40 were males and 32 were females, and the sexes were approximately equally represented in all groups.

\section{APPARATUS}

The laboratory and GSR recording equipment are described elsewhere (Hill, 1969 ). The $\mathrm{CS}$ was a $1,000-\mathrm{Hz}$ tone at $50 \mathrm{~dB}$ superimposed on a constant background of white noise generated by a Grason-Stadler twin oscillator and to acquisition and from acquisition to delivered through Clevite earphones worn by $\mathrm{S}$. The UCS was a shock produced by an Applegate constant-current apparatus, Model 250, and delivered through zinc electrodes attached to the tips of the index and fourth finger of S's right hand. Each S was signaled either to try to inhibit or to facilitate his responses on different trials by one of two panels located approximately $5 \mathrm{ft}$ directly in front of him and mounted at eye level. As a signal, one or the other of the two panels was illuminated to show either the word "YES" (facilitate) or the word "NO" (inhibit). The panel was illuminated during the entire intertrial interval (ITI) preceding a trial except for a period of 5 sec following any given trial, during which time neither panel was illuminated. Groups were counterbalanced as to left-right position of the signal. The ITI varied randomly from 25 to $45 \mathrm{sec}$, with a mean of $35 \mathrm{sec}$. A response was defined as the maximum deflection occurring within the interval defined by the onset of the CS and $3 \mathrm{sec}$ following the offset of the CS.

\section{PROCEDURE}

Twenty-four Ss were assigned randomly to each of three treatment conditions: 500 -, 2,000 , or $4,000-\mathrm{msec}$ ISI. The UCS duration was $100 \mathrm{msec}$ and was coterminous with the CS. The first part of the tape-recorded instructions was designed to equate $S s$ in their degree of knowledge about the conditioning procedure in general. The second part included a detailed description of the stimulus events to be experienced during adaptation, acquisition, and extinction. The Ss were also told that a signal would occur before each trial during all parts of the experiment, and that they were to try to facilitate or to inhibit their responses, according to the signal. It was suggested to Ss that they could control their GSR through their attitude (on facilitatory trials they were told to assume an attitude of "The tone means that a shock is coming very soon, so I might as well prepare for it"; on inhibitory trials, an attitude of "Why should I respond to the tone; it doesn't do anything").

Each $S$ received four UCS adaptation trials prior to the onset of conditioning, with the signals presented in an ABBA or $B A A B$ counterbalanced fashion. All Ss received 10 conditioning trials, with reinforcement delivered on every trial. These 10 trials were followed by 16 extinction trials. The signal panels were illuminated in a fixed random order, with the restriction that no more than two facilitatory or two inhibitory trials occur in succession. Occurrence of the signal during extinction was also in a fixed random order. with the additional restriction that 
Table 1

Mean Log Magnitude GSR for Facilitatory and Inhibitory Trials for Acquisition and Extinction

\begin{tabular}{cccccc} 
ISI & \multicolumn{2}{c}{ Acquisition } & & \multicolumn{2}{c}{ Extinction } \\
\cline { 2 - 3 } \cline { 5 - 6 } M & $\begin{array}{c}\text { Facec) } \\
\text { tatory }\end{array}$ & $\begin{array}{c}\text { Inhibi- } \\
\text { tory }\end{array}$ & & $\begin{array}{c}\text { Facili- } \\
\text { tatory }\end{array}$ & $\begin{array}{c}\text { Inhibi- } \\
\text { tory }\end{array}$ \\
\hline 500 & 2.49 & 2.44 & 1.36 & 1.19 \\
2000 & 2.48 & 2.38 & & 1.20 & 1.04 \\
4000 & 2.61 & 2.52 & & 1.09 & .88 \\
\hline
\end{tabular}

each four-trial block include two inhibitory and two facilitatory trials. The resulting fixed random order was reversed for o ne-half the Ss in an attempt to counterbalance for changes occurring as a result of the acquisition and extinction processes. The data for these two orders were subsequently combined for the overall analysis.

\section{RESULTS}

The GSR scores were transformed according to the formula:

$$
\log \left[\left(\frac{1}{\mathrm{Ra}}-\frac{1}{\mathrm{Rb}}\right) \times 10^{8}+1\right]
$$

where $\mathrm{Rb}$ is the resistance at the moment of initiation of the response and $\mathrm{Ra}$ is the resistance at the peak of the response. For each group the mean $\log$ magnitude GSR for facilitatory and inhibitory trials during acquisition and extinction were computed and are presented in Table 1.

Separate ISI by Instructions analyses of variance were performed for acquisition and extinction data. For acquisition the main effect of instructions was significant $[F(1,69)=16.50, p<.01]$, with facilitatory trials yielding larger response magnitudes than did inhibitory trials. Similarly, for extinction data a significant main effect of instructions was found $[F(1,69)=8.62, \quad p<.01]$, with larger response magnitudes on facilitatory than on inhibitory trials. No significant interactions were found in either acquisition or extinction, indicating that $\mathrm{Ss}^{\circ}$ ability to respond in accordance with instructions did not vary as a function of ISI. No main effect of ISI was found for either acquisition or extinction.

In addition, the 16 extinction trials were divided into four trial blocks, each consisting of two facilitatory and two inhibitory trials, and were analyzed. An ISI by Trial Blocks by Instructions analysis of variance was performed, revealing a significant main effect of trial blocks $[F(3,207)=23.04, p<.01]$ and indicating that, overall, extinction did occur. Also, a significant main effect of instructions was found $[F(1,207)=9.74, p<.01]$, with facilitatory trials yielding higher response magnitudes than did inhibitory trials. The ISI by Trial Blocks interaction was marginally significant $[F(6,207)=2.23$ $p<.05]$, indicating that the slopes of the curves for the three ISI groups differed, apparently due to a differential shift among groups from Trial Block 1 to Trial Block 2. None of the other interactions was significant, indicating that the three ISI groups appeared to be no more or less able to respond according to instructions at one point in extinction than at another and, in addition, did not differ significantly from each other in this respect.

\section{DISCUSSION}

The results support previous findings, that the behavior of Ss in the GSR conditioning situation can be significantly affected by instructional set, again pointing out the importance of controlling both stimulus set and response set in the conditioning situation. In particular, the present results indicate that Ss can adopt, upon signal, either a facilitatory or inhibitory verbally induced response set and effectively mobilize it on the next acquisition or extinction trial, pointing specifically to a need for consideration of within-session changes in Ss' sets and attitudes. It is noteworthy that differences were found in acquisition even though the shock UCS was present on every trial.

Since the predicted ISI by Instructions interaction was not significant, it appears that mobilization of the response sets was not dependent upon an extended CS-UCS interval. From this, it would appear reasonable to suggest that giving Ss ample time to adopt a response set is a necessary and sufficient condition for differential responding in a situation such as this. That is, perhaps once a response set has been adopted for any particular trial (or experiment), a relatively short ISI (such as $500 \mathrm{msec}$ ) is sufficient time for its mobilization, and any longer time does not add anything insofar as responding in accordance with instructions is concerned. To some extent, the present results are consistent with those reported by Wickens \& Harding (1967), in which ISI was not a crucial variable affecting differential responding during extinction for Ss forewarned about which of two CSs (one with an expectancy of shock and the other with an expectancy of no shock, achieved through deceptive instructions) was to occur next. That is, one might argue that giving Ss forewarning about whether or not to expect shock on the next trial (although no shock was again given) is analogous to signaling Ss in advance whether to adopt a facilitatory or an inhibitory response set for the next trial.

On the other hand, Wickens \& Harding (1967) found ISI to be an important variable for $S s$ who were not forewarned which CS was to occur next (the differential expectancies were again induced). These investigators based their explanation on the assumption that discrimination of one stimulus event from another requires a longer time interval than simply detecting that a stimulus has occurced. They argue that in the forewarned groups, discrimination is achieved in advance by the warning signal and, hence, ISI becomes unimportant. That is, it is not necessary for the forewarned $S$ to discriminate which signal is being presented in order to respond appropriately, but rather simply to detect that one has occurred. It is being suggested here that regardless of whether different response sets are induced by stimulus expectancy (as in the Wickens and Harding study) or by response-set instructions (as in the present study), if the discrimination process stage is eliminated by "forewarning," the CS-UCS interval is no longer a critical variable. An experiment in which the CSs were also the instructional signals would be a logical step to take from here. In this situation, an ISI by Instructions interaction would be predicted.

\section{REFERENCES}

COOK, S. W., \& HARRIS, R. E. The verbal conditioning of the galvanic skin reflex. Journal of Experimental Psychology, 1937, 21, 202-210.

GRINGS, W. W., \& LOCKHART, R. A. Effects of "anxiety-lessening" instructions and differential set development on the extinction of the GSR. Journal of Experimental Psychology, 1963, 64, 131-136.

HILL, F. A. The effects of instructions and subject's need for approval on the GSR. Journal of Experimental Psychology, 1967. 73, 461-467.

HILL, F. A. Effects of UCS predictability in GSR conditioning. Psychonomic Science, 1969, 17, 195-196:

MOWRER, O. H. Preparatory set (expectancy): A determinant in motivation and learning. Psychological Review, 1938, 45, 62-91.

SPENCE, K. W., RUTLEDGE, E. F., \& TALBOTT, J. H. Effect of number of acquisition trials and the presence or absence of the UCS on extinction of the eyelid CR. Journal of Experimental Psychology, 1963, 66, 286-291.

WICKENS, D. D., ALLEN, C. K., \& HILL, F. A. Effect of instructions and UCS strength on extinction of the conditioned GSR. Journal of Experimental Psychology, 1963, 66, 235-40.

WICKENS, D. D., \& HARDING, G. B. Effects of interstimulus interval, forewarning, and instructions on extinction of the GSR. Joumal of Experimental Psychology. 1967, 74. 363-369. 